\title{
Erratum zu: Kinderpornografie
}

\section{Übersicht und aktuelle Entwicklungen}

\author{
Irina Franke ${ }^{1} \cdot$ Marc Graf $^{1}$
}

Online publiziert: 22. Juli 2016

(c) Der/die Autor(en) 2016

\section{Erratum zu:}

Forensische Psychiatrie, Psychologie, Kriminologie 2016 DOI 10.1007/s11757-016-0361-8

In der Originalpublikation dieses Beitrags enthält der Abschnitt „Opfer“ leider einen Fehler.

Korrekt ist die Angabe: „Eine Untersuchung aus dem Jahr 2005 unter Personen, die wegen des Besitzes von Kinderpornografie verhaftet worden waren, zeigte, dass über $80 \%$ der Personen Bilder von präpubertären Kindern besaßen und $80 \%$ Bilder besaßen, die das Penetrieren von Kindern zeigten; ....

Wir bitten um Beachtung und entschuldigen uns für den Fehler.

Die Online-Version des Originalartikels ist unter doi:10.1007/ s11757-016-0361-8 zu finden.

$\triangle$ Dr. med. Irina Franke

Irina.Franke@upkbs.ch

1 Forensisch-Psychiatrische Klinik, Universitäre Psychiatrische Kliniken Basel, Wilhelm-Klein-Str. 27, 4012 Basel, Schweiz 